\title{
Monitoring aboveground biomass in semiarid grasslands using MODIS images
}

\author{
Tomoko NAKANO ${ }^{*}{ }^{\dagger}$, Ganbat BAVUUDORJ**, Nachinshonhor G. URIANHAI***, \\ and Masato SHINODA**** \\ $\left(\begin{array}{c}* \text { Faculty of Economics, Chuo University, 742-1 Higashinakano, Hachioji, 192-0393, Japan } \\ * * \text { Institute of Meteorology, Hydrology and Environment, } 5 \text { Hudaldaa street, Ulaanbaatar, 210646, Mongolia } \\ * * * \text { Graduate School of Environmental and Life Science, Okayama University, } \\ 3-1-1 \text { Tsushima-naka, Kita-ku, Okayama, 700-8530, Japan } \\ * * * * \text { Arid Land Research Center, Tottori University, } 1390 \text { Hamasaka, Tottori, 680-0001, Japan }\end{array}\right)$
}

\begin{abstract}
In the present study, we calculated seven vegetation indices (simple ratio [SR], normalized difference vegetation index [NDVI], enhanced vegetation index [EVI], soil-adjusted vegetation index [SA$\mathrm{VI}$, optimized soil-adjusted vegetation index [OSAVI], land surface water index [LSWI], and greenery ratio [GR]) based on MODIS surface reflectance data and analyzed the relationships between these indices and the aboveground biomass in semiarid grasslands in Mongolia. The measured values of the biomass for the study area ranged from 7.5 to $137.0 \mathrm{~g}$ dry weight $(\mathrm{dw}) \mathrm{m}^{-2}$. The results revealed that NDVI, SR, and OSAVI were strongly correlated with the biomass. Among these, NDVI showed the best performance as a proxy of the plant biomass of Mongolian grasslands. The relationships of NDVI and OSAVI with the temporal variation and spatial pattern of biomass were statistically similar, suggesting that a single linear equation was appropriate to derive aboveground biomass values from NDVI or OSAVI.
\end{abstract}

Key words: Aboveground biomass, MODIS, Semiarid grassland, Vegetation index.

\section{Introduction}

The exchange of carbon dioxide between the atmosphere and terrestrial ecosystems is strongly related to the amount of growing plants (e.g., Flanagan et al., 2002; Xu and Baldocchi, 2004; Nakano et al., 2008; Nakano and Shinoda, 2010). Therefore, accurate monitoring of vegetation dynamics is required for estimating the spatial and temporal variabilities of terrestrial ecosystem carbon exchange and climate-biosphere interactions. Because satellite remote sensing can provide consistent and systematic observation of vegetation and ecosystems, it is a good tool for monitoring the large spatial heterogeneity and temporal dynamics of ecosystems across complex landscapes and regions. Several vegetation indices based on satellite reflec-

Received; August 27, 2012.

Accepted; October 31, 2012.

†Corresponding Author: nakanot@tamacc.chuo-u.ac.jp tance data (e.g., the normalized difference vegetation index [NDVI] and enhanced vegetation index [EVI]) have been proposed since the 1970s, and studies have shown that these indices were strongly related to the leaf area index (Kimura et al., 2004), green biomass (Nandintsetseg et al., 2010), seasonal phenology (Huete et al., 2002), and interannual vegetation change (Eerdeni et al., 2009) .

In the present study, we computed seven vegetation indices (simple ratio [SR], NDVI, EVI, soil-adjusted vegetation index [SAVI], optimized soil-adjusted vegetation index [OSAVI], land surface water index [LSWI], and greenery ratio [GR]) from reflectance data of the Moderate Resolution Imaging Spectral radiometer (MODIS) and examined the relationships between these indices and values of aboveground biomass (AGB) measured in semiarid grasslands of Mongolia. The objectives of this study were to determine the most suitable index for monitoring the plant AGB in semiarid grasslands and to investigate whether 
the temporal and spatial relationships between each index and biomass were statistically similar.

\section{Materials and Methods}

\subsection{Field measurements of aboveground biomass}

The study area is located in the semiarid region of central Mongolia $\left(46.0^{\circ}\right.$ to $48.0^{\circ} \mathrm{N}, 105.0^{\circ}$ to $110.0^{\circ} \mathrm{E}$, elevation ranges from ca. 1000 to $1500 \mathrm{~m}$ above sea level; Fig. 1). A meteorological station of the Institute of Meteorology, Hydrology, and Environment of Mongolia (IMHE) is located adjacent to site BU-G. Data from the IMHE station indicated that the mean annual air temperature and precipitation from 1995 to 2010 were $0.3^{\circ} \mathrm{C}$ and $155.8 \mathrm{~mm}$, respectively. The vegetation in the study area is that typical of steppe and is grazed by livestock. The plant community is dominated by graminaceous perennial grasses (Agropyron cristatum, Cleistogenes squarrosa, Stipa krylovii), annual forbs (Artemisia spp., Chenopodium spp.), and small shrubs (Caragana spp.). Measurements of live AGB were conducted at 12 sites from 2001 to 2011. We set 4 to 10 quadrats $(1 \times 1 \mathrm{~m})$ at each site and clipped green parts of all plants within the quadrats. Clipped plant samples were oven-dried at $80^{\circ} \mathrm{C}$ for 48 $\mathrm{h}$ and then weighed to determine their dry weights.

To examine the time domain relationships between the vegetation indices and plant biomass, AGB measurements were conducted in June, July, and August of 2004 and 2005; July and August of 2006; and August

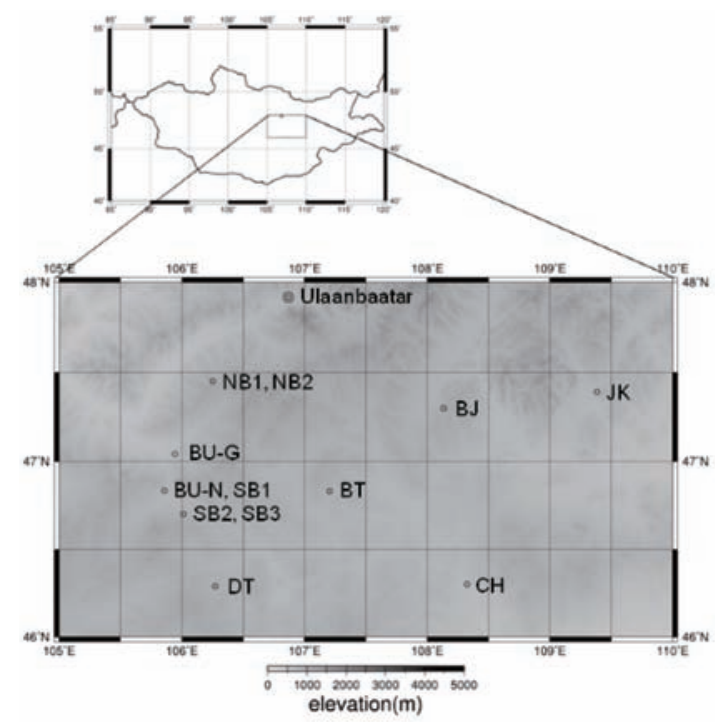

of 2008, 2009, and 2010 at site BU-G; and in lateAugust from 2001 to 2009 at site BU-N. During the summers from 2009 to 2011, spatial variability was investigated by AGB measurements at 10 sites: $\mathrm{SB} 1$ in August of 2009; NB1, NB2, SB2, and SB3 in August of 2010; BJ, BT, and DT in August of 2011; and CH and JK in September of 2011. The average values of AGB for each time and site ranged from 7.5 to $137.0 \mathrm{~g}$ dry weight $(\mathrm{dw}) \mathrm{m}^{-2}$, suggesting that vegetation in this area was very sparse compared with other grasslands in the world.

\subsection{Satellite-based vegetation indices}

The MODIS sensor onboard the Terra satellite captures an image of the study area every 1 to 2 days, with 36 spectral bands, including 7 bands that are related to vegetation. In this study, we downloaded the 8-day Land Surface Reflectance (MOD09A1) datasets from the Land Processes Distributed Active Archive Center (LP DAAC), U.S. Geological Survey (http://lpdaac.usgs.gov) to determine the vegetation indices. The MOD09A1 data covers the land surfaces at $500 \mathrm{~m}$ spatial resolution and corrections were made to the daytime data to accommodate for the effects of atmospheric gases, aerosol, and cirrus clouds. Each measurement site was matched with a MODIS pixel based on latitude and longitude information.

We examined the degree to which seven vegetation indices could serve as accurate proxies of plant biomass in semiarid grassland: SR (Jordan, 1969), NDVI (Rouse et al., 1973), EVI (Huete et al., 1997), SAVI (Huete, 1988), OSAVI (Rondeaux et al., 1996), LSWI (Xiao et al., 2002), and GR (Harazono et al., 2009). These vegetation indices are expressed by the following formulae:

$$
\begin{aligned}
\mathrm{SR}= & \rho_{\text {nir }} / \rho_{\text {red }} \\
\mathrm{NDVI} & =\left(\rho_{\text {nir }}-\rho_{\text {red }}\right) /\left(\rho_{\text {nir }}+\rho_{\text {red }}\right) \\
\mathrm{EVI}= & \mathrm{G} \times\left(\rho_{\text {nir }}-\rho_{\text {red }}\right) \\
& /\left\{\rho_{\text {nir }}+\left[\left(\mathrm{C} 1 \times \rho_{\text {red }}\right)-\left(\mathrm{C} 2 \times \rho_{\text {blue }}\right)\right]+\mathrm{L} 1\right\}
\end{aligned}
$$

$$
\mathrm{SAVI}=(1+\mathrm{L} 2) \times\left(\rho_{\text {nir }}-\rho_{\text {red }}\right) /\left(\rho_{\text {nir }}+\rho_{\text {red }}+\mathrm{L} 2\right)
$$

$$
\text { OSAVI }=\left(\rho_{\text {nir }}-\rho_{\text {red }}\right) /\left(\rho_{\text {nir }}+\rho_{\text {red }}+\mathrm{X}\right)
$$

Fig. 1. Map of the study area in central Mongolia. 


$$
\begin{aligned}
& \mathrm{LSWI}=\left(\rho_{\text {nir }}-\rho_{\text {swir }}\right) /\left(\rho_{\text {nir }}+\rho_{\text {swir }}\right) \\
& \mathrm{GR}=\rho_{\text {green }} /\left(\rho_{\text {red }}+\rho_{\text {green }}+\rho_{\text {blue }}\right)
\end{aligned}
$$

where $\rho_{\text {nir }}$, $\rho_{\text {red }}$, $\rho_{\text {green }}, \rho_{\text {blue }}$, and $\rho_{\text {swir }}$ are reflectance in the near-infrared, red, green, blue, and shortwaveinfrared bands, respectively. $\mathrm{G}=2.5, \mathrm{C} 1=6, \mathrm{C} 2=7.5$, $\mathrm{L} 1=1$ (Huete et al., 1997), L2=0.5 (Huete, 1988), and $\mathrm{X}=0.16$ (Rondeaux et al., 1996).

\section{Results and Discussion}

Correlation coefficients between the vegetation indices and the measured AGB values for temporal variation and spatial pattern are listed in Table 1. All of the vegetation indices showed significant positive correlations with the measured AGB $(P<0.01)$. For temporal variations at BU-G and BU-N, NDVI and SR were highly correlated with the AGB, followed by OSAVI. For spatial variability among the 10 sites, OSAVI and NDVI showed the highest correlations with the AGB. For the entire dataset, including the temporal and spatial variations, NDVI showed the highest correlation, followed by OSAVI.

Linear regression analysis indicated that SR, NDVI, and OSAVI showed high correlations with AGB (Fig. 2 , Table 2). To investigate whether the relationships differed significantly over time versus over space, the regression slopes were compared by analysis of covariance (ANCOVA). The analysis revealed that the differences among the temporal, spatial, and all variabilities in the slope of the relationship were not significant for NDVI and OSAVI. Consequently, a single linear equation was appropriate to derive AGB values from NDVI or OSAVI. In contrast, the time-domain relationship between $\mathrm{SR}$ and AGB was significantly different from the relationships for spatial and all vari- abilities.

SR, which directly compares signals between the reflection and absorption peak of chlorophyll pigments, was the first index to be defined (Jordan, 1969). SR was shown to be closely related to canopy chlorophyll content, leaf area index (LAI), and green leaf biomass in a winter wheat field in Girona, Spain (Serrano et al., 2000) and canopy chlorophyll content and gross primary production (GPP) in a maize field in Nebraska, USA (Peng and Gitelson, 2011). In our study, SR was highly correlated with AGB for temporal variability ( $r$ $>0.97$ ), but the correlation coefficient was lower for spatial variability $(r=0.885)$. In addition, the regression slope for temporal variation differed significantly from that for spatial pattern. Slater and Jackson (1982) reported that SR was susceptible to environmental factors, such as soil and cloud cover. Hence, the relationship between SR and AGB for spatial variability in this study may have been influenced by these disturbances.

NDVI is the most widely used vegetation index, and it is often applied in production efficiency models to estimate the vegetation productivity of terrestrial ecosystems (Nemani et al., 2003; Running et al., 2004). NDVI has several limitations, however, including sensitivity to atmospheric conditions, sensitivity to soil background, and saturation of NDVI values in multilayered and closed canopies (Xiao et al., 2004). Our analyses indicated that NDVI was the best predictor of plant biomass in the semiarid grasslands of Mongolia. This result was probably due to the sparse vegetation cover in our study area, suggesting that the relationship between NDVI and AGB did not reach saturation. Previous studies also demonstrated strong relationships between NDVI and vegetation parameters such as LAI and biomass in grasslands and croplands (e.g., Frank

Table 1. Pearson's correlation coefficients between the vegetation indices and aboveground biomass for Mongolian semiarid grasslands.

\begin{tabular}{lrccccccc}
\hline Site & \multicolumn{1}{c}{$n$} & SR & NDVI & EVI & SAVI & OSAVI & LSWI & GR \\
\hline BU-G $^{\mathrm{a}}$ & 11 & 0.971 & 0.973 & 0.848 & 0.893 & 0.945 & 0.790 & 0.902 \\
BU-N $^{\mathrm{b}}$ & 9 & 0.972 & 0.957 & 0.891 & 0.884 & 0.927 & 0.901 & 0.840 \\
Multipoint $^{\mathrm{c}}$ & 10 & 0.885 & 0.917 & 0.906 & 0.908 & 0.920 & 0.785 & 0.898 \\
All & 30 & 0.886 & 0.931 & 0.887 & 0.895 & 0.922 & 0.814 & 0.820 \\
\hline
\end{tabular}

All correlation coefficients are significant at $P<0.01$.

a Temporal variation from 2004 to 2010

${ }^{\mathrm{b}}$ Temporal variation from 2001 to 2009

'Sites BJ, BT, CH, DT, JK, NB1, NB2, SB1, SB2, and SB3 

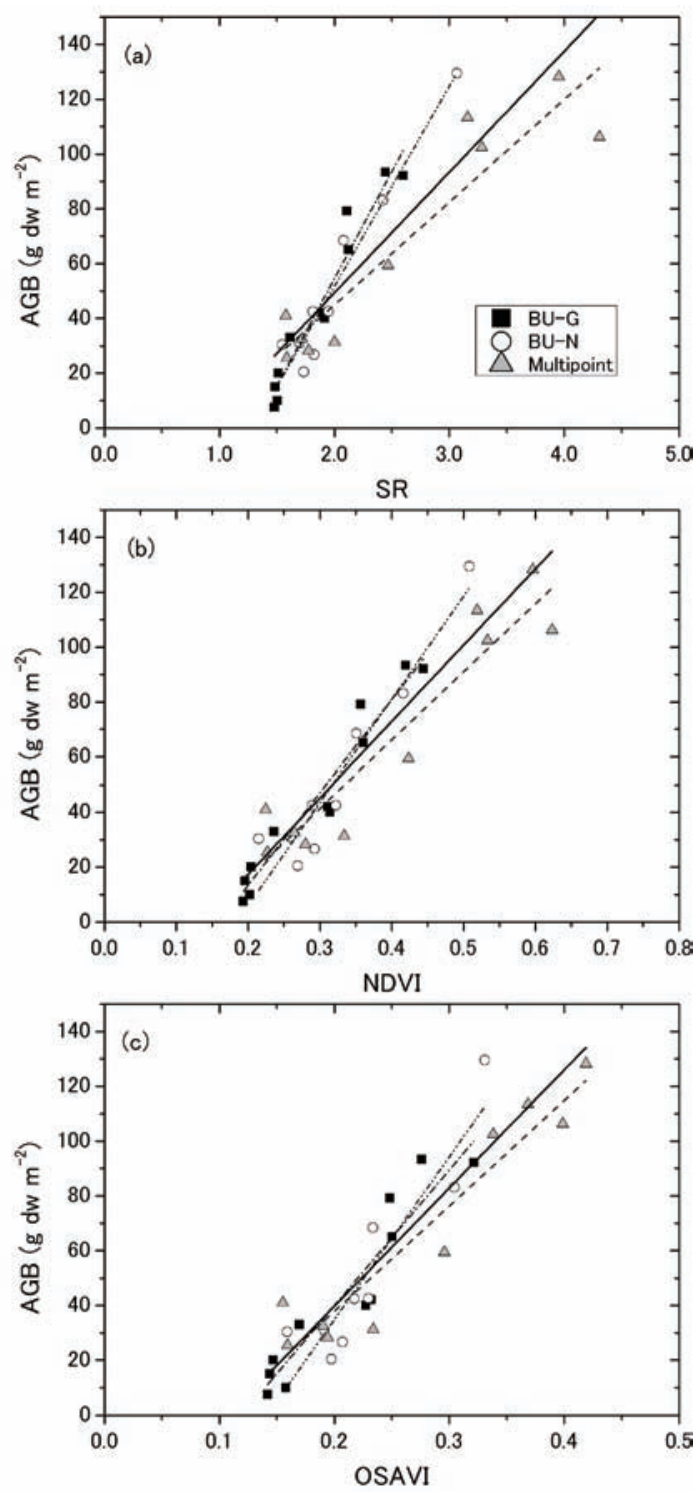

Fig. 2. Relationships between aboveground biomass (AGB) and the vegetation indices (a) simple ratio (SR), (b) normalized difference vegetation index (NDVI), and (c) optimized soil-adjusted vegetation index (OSAVI) for data of the temporal variations at sites BU-G and BU-N and the spatial pattern at multiple sites. Lines are regression lines for BU-G (dashed-dotted line), BU-N (dashed-two dotted line), multipoint (dashed line), and the entire dataset (solid line). and Karn, 2003; Kimura et al., 2004; Kawamura et al., 2005; Nandintsetseg et al., 2010; Edirisinghe et al., 2012).

Huete (1988) proposed SAVI, in an attempt to minimize brightness-related soil effects by considering the first-order soil-vegetation interaction by means of a soil-adjustment parameter. Rondeaux et al. (1996) developed OSAVI, which has the advantages of a simpler equation and lack of a requirement of prior knowledge of the soil type. Our analyses indicated that both OSAVI and NDVI were highly correlated with AGB, in agreement with previous studies. For example, Kimura et al. (2004) demonstrated strong relationships between LAI and spectral vegetation indices such as OSAVI, NDVI, and SR in an upland rice field in Tottori, Japan. Boschetti et al. (2007) examined the relationships between AGB and vegetation indices in Italian alpine pastureland. They reported that SAVI and OSAVI showed a better correlation with AGB in alpine pastureland than indices that are more often employed, such as SR and NDVI. Duan et al. (2011) reported that OSAVI had the most significant relationship with biomass and was the most appropriate vegetation index to estimate AGB in the alpine steppe ecosystem of northern Tibet.

As for EVI, LSWI, and GR, the correlation between each index and AGB was significant but not strong in the present study. EVI directly adjusts the reflectance in the red band as a function of the reflectance in the blue band, accounting for residual atmospheric contamination (e.g., aerosols) and variable soil and canopy background reflectance (Huete et al., 1997). Huete et al. (2002) evaluated the performance of MODIS NDVI and EVI data at four sites with semiarid grassland, semiarid shrubland, savanna, and tropical forest biomes in North and South America. They found that the MODIS vegetation indices represented the seasonal phenologies well over numerous biome types. Kawamura et al. (2005) also reported a good performance of MODIS NDVI and EVI data for estimating total and live biomass in the steppe area of central Inner Mongolia, China. LSWI is calculated as the normalized difference between near-infrared and shortwave-infrared spectral bands (Xiao et al., 2002). Because the shortwave-infrared spectral band is sensitive to vegetation water content and soil moisture, it can improve the discrimination of vegetation and other land cover types (Boles et al., 2004). EVI and LSWI have been used 
Table 2. Regression parameters for the linear relationships between vegetation indices and aboveground biomass.

\begin{tabular}{llrlccc}
\hline \multicolumn{1}{c}{ Index } & \multicolumn{1}{c}{ Site } & $n$ & Intercept & Slope & $R^{2}$ & SEE $^{\mathrm{a}}$ \\
\hline SR & BU-G $^{\text {b }}$ & 11 & -102.0 & 78.2 & 0.936 & 2.47 \\
& BU-N $^{\mathrm{c}}$ & 9 & -95.4 & 73.0 & 0.936 & 3.08 \\
& Multipoint $^{\mathrm{d}}$ & 10 & -30.0 & 37.5 & 0.861 & 4.84 \\
& All & 30 & -38.9 & 44.1 & 0.777 & 3.15 \\
& & & & & & \\
NDVI & BU-G $^{\mathrm{b}}$ & 11 & -54.1 & 337.2 & 0.940 & 2.38 \\
& BU-N $^{\mathrm{c}}$ & 9 & -69.1 & 375.1 & 0.905 & 3.76 \\
& Multipoint $^{\mathrm{d}}$ & 10 & -33.1 & 248.1 & 0.878 & 4.53 \\
& All & 30 & -38.3 & 277.9 & 0.861 & 2.48 \\
& & & & & & \\
OSAVI & BU-G $^{\mathrm{b}}$ & 11 & -59.2 & 495.2 & 0.880 & 3.37 \\
& BU-N $^{\mathrm{c}}$ & 9 & -84.7 & 593.8 & 0.839 & 4.89 \\
& Multipoint $^{\mathrm{d}}$ & 10 & -39.1 & 384.6 & 0.892 & 4.26 \\
& All & 30 & -46.6 & 431.2 & 0.845 & 2.66 \\
\hline
\end{tabular}

All regressions are significant at $P<0.01$.

${ }^{a} \mathrm{SEE}$ indicates standard error of the estimate.

${ }^{b}$ Temporal variation from 2004 to 2010

${ }^{\mathrm{c}}$ Temporal variation from 2001 to 2009

${ }^{\mathrm{d}}$ Sites BJ, BT, CH, DT, JK, NB1, NB2, SB1, SB2, and SB3

widely to characterize the growing conditions of vegetation (Zhang et al., 2003; Boles et al., 2004) and to estimate GPP as model input parameters (Li et al., 2007; Wang et al., 2010). GR is a relatively new index proposed by Harazono et al. (2009) as a simple ratio of green to total visible bands. They found a high correlation between GR and GPP at a rice paddy in Japan and applied GR to estimate the carbon dioxide budget. Their model provided good predictions of the daily magnitudes and seasonal trends of GPP for the rice paddy.

In this study, linear regression analysis and ANCOVA indicated that a single linear equation was appropriate to derive AGB values from NDVI or OSAVI. Several other studies have examined the relationship between vegetation indices and plant parameters over time and over space. For example, Frank and Karn (2003) examined the relationship between NDVI and plant parameters such as LAI and biomass over 3 years for three types of grasslands in the northern Great Plains, USA. They found that the relationships between NDVI and plant parameters for all years and sites were similar, which is consistent with our results. Edirisinghe et al. (2012) examined the relationship between satellite-derived NDVI and field-measured pasture biomass in New Zealand. They collected biomass data 10 times from May to December 2006 at 10 farms in their target area $(60 \times 60 \mathrm{~km})$ and investigated the effects of time and space on the relationship between NDVI and biomass. The study revealed that the logarithm of pasture biomass was linearly related to NDVI and that the relationship showed a significant dependence on time over the season and no dependence on space across the scene at a given time. In contrast, we found that the time and space domain relationships were similar for semiarid grasslands in Mongolia. Although Edirisinghe et al. (2012) did not mention the degree of the time effect on the NDVI-biomass relationship, differences in plant species and the higher biomass value (up to $400 \mathrm{~g} \mathrm{dw} \mathrm{m}^{-2}$ ) in their study area might have caused their results to differ from our results.

\section{Conclusions}

We examined the relationships between satellitederived vegetation indices and field-measured AGB in semiarid grasslands in Mongolia. Among the vegetation indices, NDVI showed the best performance as a proxy of plant biomass in the Mongolian grasslands. The time domain and space domain relationships be- 
tween the biomass and NDVI and OSAVI were statistically similar, suggesting that a single linear equation is appropriate to derive AGB values from NDVI or OSAVI.

\section{Acknowledgements}

This research was funded by Chuo University (Grant for Special Research); Arid Land Research Center, Tottori University (Grants for Joint Research); Social Welfare Corporation Nanko Airinkai (Special Grant); Japan Society for the Promotion of Science (Grant no.19-07308 ); National Museum of Ethnology (Grant for Joint Research); Research Institute for $\mathrm{Hu}-$ manity and Nature (Grant no. D-04); and the Ministry of Education, Sports, Culture, Science and Technology of Japan (Grants-in-Aid nos. 22510017, 20255001, 18202024, 14252012, and 12575003).

\section{References}

Boles, S. H., Xiao, X., Liu, J., Zhang, Q., Munkhtuya, S., Chen, S., and Ojima, D., 2004: Land cover characterization of temperate East Asia using multitemporal VEGETATION sensor data. Remote Sens. Environ., 90, 477-489.

Boschetti, M., Bocchi, S., and Brivio, P. A., 2007: Assessment of pasture production in the Italian Alps using spectrometric and remote sensing information. Agric. Ecosyst. Environ., 118, 267-272.

Duan, M., Gao, Q., Wan, Y., Li, Y., Guo, Y., Gnazhu, Z., Liu, Y., and Qin, Z., 2011: Biomass estimation of alpine grasslands under different grazing intensities using spectral vegetation indices. Can. J. Remote Sens., 37, 413-421.

Edirisinghe, A., Clark, D., and Waugh, D., 2012: Spatio-temporal modelling of biomass of intensively grazed perennial dairy pastures using multispectral remote sensing. Int. J. Appl. Earth Obs. Geoinformation, 16, 5-16.

Eerdeni, Hotta, N., and Suzuki, M., 2009: Vegetationchange detection in Inner Mongolia using NOAA/AVHRR images between 1982 and 1999. J. Jpn. Soc. Reveg. Technol., 35, 338-350 (in Japanese with English summary).

Flanagan, L. B., Wever, L. A., and Carlson, P. J., 2002: Seasonal and interannual variation in carbon dioxide exchange and carbon balance in a northern temperate grassland. Glob. Change Biol., 8, 599-615.

Frank, A. B., and Karn, J. F., 2003: Vegetation indices,
$\mathrm{CO}_{2}$ flux, and biomass for Northern Plains grasslands. J. Range Manag., 56, 382-387.

Harazono, Y., Chikamoto, K., Kikkawa, S., Iwata, T., Nishida, N., Ueyama, M., Kitaya, Y., Mano, M., and Miyata, A., 2009: Applications of MODIS-visible bands index, greenery ratio to estimate $\mathrm{CO}_{2}$ budget of a rice paddy in Japan. J. Agric. Meteorol., 65, 365-374.

Huete, A. R., 1988: A soil-adjusted vegetation index (SAVI) . Remote Sens. Environ., 25, 295-309.

Huete, A., Didan, K., Miura, T., Rodriguez, E. P., Gao, X., and Ferreira, L. G., 2002: Overview of the radiometric and biophysical performance of the MODIS vegetation indices. Remote Sens. Environ., 83, 195213.

Huete, A. R., Liu, H. Q., Batchily, K., and van Leeuwen, W., 1997: A comparison of vegetation indices over a global set of TM images for EOS-MODIS. Remote Sens. Environ., 59, 440-451.

Jordan, C. F., 1969: Derivation of leaf-area index from quality of light on the forest floor. Ecology, 50, 663666.

Kawamura, K., Akiyama, T., Yokota, H., Tsutsumi, M., Yasuda, T., Watanabe, O., and Wang, S., 2005: Comparing MODIS vegetation indices with AVHRR NDVI for monitoring the forage quantity and quality in Inner Mongolia grassland, China. Grassland Sci., 51, 33-40.

Kimura, R., Okada, S., Miura, H., and Kamichika, M., 2004: Relationships among the leaf area index, moisture availability, and spectral reflectance in an upland rice field. Agric. Water Manag., 69, 83-100.

Li, Z., Yu, G., Xiao, X., Li, Y., Zhao, X., Ren, C., Zhang, L., and Fu, Y., 2007: Modeling gross primary production of alpine ecosystems in the Tibetan Plateau using MODIS images and climate data. Remote Sens. Environ., 107, 510-519.

Nakano, T., and Shinoda, M., 2010: Response of ecosystem respiration to soil water and plant biomass in a semiarid grassland. Soil Sci. Plant Nutr., 56, 773781.

Nakano, T., Nemoto, M., and Shinoda, M., 2008: Environmental controls on photosynthesis production and ecosystem respiration in semi-arid grasslands of Mongolia. Agric. For. Meteorol., 148, 1456-1466.

Nandintsetseg, B., Shinoda, M., Kimura, R., and Ibaraki, Y., 2010: Relationship between soil moisture and vegetation activity in the Mongolian steppe. SOLA, 6, 29-32. 
Nemani, R. R., Keeling, C. D., Hashimoto, H., Jolly, W. M., Piper, S. C., Tucker, C. J., Myneni, R. B., and Running, S. W., 2003: Climate-driven increases in global terrestrial net primary production from 1982 to 1999. Science, 300, 1560-1563.

Peng, Y., and Gitelson, A. A., 2011: Application of chlorophyll-related vegetation indices for remote estimation of maize productivity. Agric. For. Meteorol., 151, 1267-1276.

Rondeaux, G., Steven, M., and Baret, F., 1996: Optimization of soil-adjusted vegetation indices. Remote Sens. Environ., 55, 95-107.

Rouse, J. W., Haas, R. H., Schell, J. A., and Deering, D. W., 1973: Monitoring vegetation systems in the Great Plains with ERTS. Proc. Third ERTS Symposium, NASA SP-351, Vol. 1, 309-317.

Running, S. W., Nemani, R. R., Heinsch, F. A., Zhao, M., Reeves, M., and Hashimoto, H., 2004: A continuous satellite-derived measure of global terrestrial primary production. Bioscience, 54, 547-560.

Serrano, L., Filella, I., and Peñuelas, J., 2000: Remote sensing of biomass and yield of winter wheat under different nitrogen supplies. Crop Sci., 40, 723-731.

Slater, P. N., and Jackson, R. D., 1982: Atmospheric effects on radiation reflected from soil and vegetation as measured by orbital sensors using various scanning directions. Appl. Opt., 21, 39233931.

Wang, Z., Xiao, X., and Yan, X., 2010: Modeling gross primary production of maize cropland and degraded grassland in northeastern China. Agric. For. Meteorol., 150, 1160-1167.

Xiao, X., Boles, S., Liu, J., Zhuang, D., and Liu, M., 2002: Characterization of forest types in northeastern China, using multi-temporal SPOT-4 VEGETATION sensor data. Remote Sens. Environ., 82, 335348.

Xiao, X., Hollinger, D., Aber, J., Goltz, M., Davidson, E. A., Zhang, Q., and Moore III, B., 2004: Satellitebased modeling of gross primary production in an evergreen needleleaf forest. Remote Sens. Environ., 89, 519-534.

Xu, L., and Baldocchi, D. D., 2004: Seasonal variation in carbon dioxide exchange over a Mediterranean annual grassland in California. Agric. For. Meteorol., 123, 79-96.

Zhang, X., Friedl, M. A., Schaaf, C. B., Strahler, A. H., Hodges, J. C. F., Gao, F., Reed, B. C., and Huete, A., 2003: Monitoring vegetation phenology using MODIS. Remote Sens. Environ., 84, 471-475. 